\title{
Investigating of artificial neural network potential to predict the properties of refined raw sugar beet juice by electrocoagulation process
}

\author{
Maliheh Zarifpoor, Vahid Hakimzadeh
} Department of Food Science and technology, Quchan Branch,
Islamic Azad University, Quchan, Iran

\section{Keywords:}

Sugar beet

Refine

Electrocoagulation

Neural network

Levenberg

Correlation

\section{Article history:}

Received

01.05.2018

Received in revised

form 20.07.2018

Accepted

27.12.2018

Corresponding

author:

Vahid Hakimzadeh

E-mail:

v.hakimzadeh@

yahoo.com

DOI:

$10.24263 / 2304-$

974X-2018-7-4-12

\section{Abstract}

Introduction. In this study, based on the high potential of electrocoagulation in the removal of suspended matter and also due to high energy consumption in traditional treatment, the potential of EC was modeled by artificial neural network on purification of raw beet syrup.

Material and Methods. The potential of neural network in prediction of turbidity, color and purity of raw beet juice was investigated with different parameters as voltage $(5,10$ and 15 volts) $\mathrm{pH}(6,7$ and 8$)$ and time (regular time intervals from 1 to 60 min) during electrocoagulation process. ANN modeling was carried out by Neurosolution software v6 to determine the best type of transport function, learning rule, and determination of applied percentages for training, validation and testing stages based on their mean square errors, mean square normalized errors, mean absolute errors and correlation coefficients.

Results and discussion. The best neural network with maximum correlation coefficient for turbidity and purity obtained in Levenberg learning law and tangent transfer function which included 8 and 17 neurons respectively. Also, the best correlation coefficient and the less mean square error for color modeling related to a network with one hidden layer and 9 neurons that learned under levenberge learning law and sigmoid transfer function. Modeling was carried out with different percentages of data for training, validation and testing that the best prediction correlation for turbidity and purity obtained when $55 \%$ of the data were used for training, $40 \%$ of them were employed for validation and $5 \%$ of the data were used for testing, whereas the best percentage of learning, validation and testing for color prediction were 60,30 and 10 , respectively. The predicted values of models had suitable correlation with experimental data, so that correlation coefficient with experimental data of turbidity, color and purity were 0.999 , 0.997 and 0.990 , respectively. This study also addressed the model sensitivity to input data. The most model sensitivity of the model for prediction of turbidity, color and purity was related to voltage.

Conclusion. The model was able to predict the turbidity, color and purity of the syrup under various operating conditions, as the modeling data showed a high correlation with the experimental data. 


\section{Introduction}

In electrocoagulation process, suspended particles, emulsions or dissolved pollutants in an aqueous medium are destabilized by electrical current. Electrocoagulation process is used to purify a wide range of water and wastewater systems, remove minerals, pollutants and pathogens (Emamjomeh, 2009). The principle of electrocoagulation process is oxidation of anodes and the production of $\mathrm{Fe}^{+2}$ and $\mathrm{Al}^{+3}$ ions. In the process, metal ions are combined with electrolysis of hydroxyl ions around the cathode and produce metal hydroxides which cause the volatility of the pollutants and the creation of suspended particles or so-called Flock. The formed flocks can be floated on the liquid surface based on density differences or with the help of hydrogen bubbles generated in the cathode, or removed by settling (Chaturvedi, 2013). In general, the mechanism of removal of impurities in the EC process involves coagulation, surface absorption, settling and floating that occurred by the following reactions on the electrodes as follows:

The reactions around anode: $\mathrm{Al}=\mathrm{Al}^{3+}+3 \mathrm{e}^{-}$

The reaction around cathode: $3 \mathrm{H}_{2} \mathrm{O}+3 \mathrm{e}^{-}=3 / 2 \mathrm{H}_{2}+3 \mathrm{OH}^{-}$

Create Aluminum flocks: $\mathrm{Al}^{3+}+3 \mathrm{OH}^{-}=\mathrm{Al}(\mathrm{OH})_{3}$

The produced ions as $\mathrm{Al}^{3+}$ and $\mathrm{OH}^{-}$during the above reactions are formed in the monomers such as $\mathrm{Al}(\mathrm{OH})^{2+}, \mathrm{Al}(\mathrm{OH})^{2+}, \mathrm{Al}_{2}(\mathrm{OH})_{2}{ }^{4+}$ and $\mathrm{Al}(\mathrm{OH})^{4-}$ or polymers such as $\mathrm{Al}_{6}(\mathrm{OH})_{15}{ }^{3+}, \mathrm{Al}_{7}(\mathrm{OH})_{17^{4+}}, \mathrm{Al}_{8}(\mathrm{OH})_{20}{ }^{4+}, \mathrm{Al}_{13} \mathrm{O}_{4}(\mathrm{OH})_{24}{ }^{7+}$ and $\mathrm{Al}_{13}(\mathrm{OH})_{34}{ }^{5+}$, which eventually converted to $\mathrm{Al}(\mathrm{OH})_{3}$ and precipitated (Kobya, 2003). Because of the insolubility of iron or aluminum hydroxides in water, the low price and availability of these two metals compared to other metals with similar properties, these are used as electrodes in the EC process (Parga, 2005). In addition, can be mentioned to the other benefits of this method such as the use of simple equipment, low initial investment and operating cost, without the need of chemicals, low sludge production, larger flocks production, stable and acid resistant flocks, faster filtration, removal of small colloidal particles and less need for repair and maintenance (Chen, 2004; Myousuf, 2001; Malakootian, 2009).

One of the studies that have been done in this area is the investigation of Shivayogimat et al (2013) who used electrocoagulation process to refine sugar industry wastewater. The results of these researchers showed that the EC process using by iron electrodes could be used as an economical process to replace the traditional process of sugar refinery wastewater treatment. Zoe et al. also used the electrocoagulation method to recover the beneficial compounds from the sewage treatment of egg processing units. The results of this study showed that electrocoagulation can be used successfully for the treatment of egg wastewater and recycle valuable compounds such as high protein digestible protein and fat. Furthermore, Bazrafshan et al. concluded that electrocoagulation is a suitable method for the removal of BOD, COD and other contaminants for the treatment of dairy wastewater. Azizi et al (2016) during purification of raw sugar beet juice using by EC process reached to better value of turbidity and purity in refined juice, but they associated the slightly increasing in color to the floatation. On the other hand, modeling can play an important role in predicting system performance, determination the impact of operational variables and design processes. Neural networks are capable of modeling nonlinear and complex systems with a large number of input and output data (Delgerange, 1998). The artificial neural network system is inspired by the brain and the neural network system of the human and the same of human brain is composed of a large number of neurons that like the human brain have ability to learning. In cases where there is a large amount of input and output information for a system and we want to provide a model for that system or when we want to obtain a structure from the available information, the use of artificial neural networks can be useful. So far, for neural networks, 
various applications have been introduced with a wide range of topics (Menhaj, 2000). Therefore, researchers have shown special interest in modeling of separation processes in various industries. For example, Maskioula et al. due to membrane fouling in the ultrafiltration process in emulsion solutions introduced an experimental model for predicting the cake layer created with suitable correlation coefficient with experimental data. In 2011, Shahidi and colleagues examined the potential of nanofiltration treatment in sugar beet pulp press water, and then modeling this process with a neural network.

Therefore, in this study, based on the high efficiency of electrocoagulation in the removal of suspended matter and also due to reduce environmental problems and high energy consumption in traditional treatment of sugar beet syrup, the potential of this process was modeled on purification of raw beet syrup by artificial neural network to predict the refining properties of raw sugar beet juice that will process at another operational parameter.

\section{Materials and methods}

\section{EC process}

The data of this study were empirically and on a laboratory scale from a batch pilot. Raw sugar beet juice was produced from Chenaran sugar factory. The electrocoagulation pilot was consisted of a 5-liter reservoir. Also three electrodes made of aluminum as anode and three electrodes of iron as a cathode with a distance of $0.05 \mathrm{~m}$ and with a side area of $0.01875 \mathrm{~m} 2$ for each electrode and single-pole mode connected to an electrical power supplied (figure1). Independent variables were considered as inputs of the neural network at three levels of voltage (5,10 and 15 volts), three $\mathrm{pH}$ levels $(6,7$ and 8$)$ and six equal time intervals of 1 to 60 minutes. Turbidity, color and purity of syrup were tested as dependent variables or network outputs (Azizi, 2017).

\section{Assays}

\section{Color measurement}

Measurement of syrup color after reading its absorbance at $420 \mathrm{~nm}$ was calculated by the UNICO 2100 model spectrophotometer and according to the ICUMSA standard on the basis of equation 1(ICUMSA, GS 9/1/2/3-8, 2011).

$$
\text { Color }(\text { ICUMSA })=10^{5} \mathrm{~A} /(L \times R D S \times \rho)
$$

where $\mathrm{A}$ is absorption, $\mathrm{L}$ is the length of cell, RDS is the refractometer dry solids and $\rho$ is density.

\section{Turbidity}

Syrup turbidity with turbidometer model AL450T-IR based on NTU unit was directly obtained.

\section{Purity}

In order to calculate the purity, after obtaining pol (sucrose percentage) with Saccharometer (Model, NIR W2) and its Brix with NAR-1T model refractometer based on equation 2 (ICUMSA, GS 1/2/3/9-1, 2011).

$$
\text { Purity }=\frac{\text { Pol }}{\text { Brix }} \times 100
$$




\section{Artificial neural network modeling}

The modeling based on neural network was carried out using the Nerosolution software version 6 . In order to evaluate different networks, data were randomly divided into three parts, so that different percentage of data for training, validation and testing of network were selected. During the training process, artificial neural networks were learnt with the data until the best of relationship between neurons in each training cycle are found so that the predicted values approach the desired output values and the error values obtained at the least. To find a suitable architecture, the Mean Error Square (MSE), Mean Absolute Error (MAE) and Correlation Coefficient $\left(\mathrm{R}^{2}\right)$ were considered (Razavi, 2003). First, the total of the data (54) was completely randomized, and then the network structure with a hidden layer and the number of different neurons was studied under the Lavenberg and Momentum learning law and the two tangent and sigmoid transfer functions. Also, the best percentage of data was determined for training, validation and testing of this network. Finally, the sensitivity of changes in purity, hardness and percentage of non-sugar compounds rejection as well as temperature, time and pressure were evaluated. For estimating the model, the correlation coefficient between predicted and experimental data was also calculated (Shahidi, 2012).

\section{Results and discussion}

To find the best configuration of the artificial neural network, different networks with the number of neurons 2 to 20 were designed, according to tables 1 to 3 , the mean squares of errors, the mean square of the normalized error, the mean absolute error, and the correlation coefficient of each neuron separately in the learning laws mentioned with various functions was studied. In the following, the best percentage of data used for network training, validation and testing with the least error and the highest correlation coefficient was investigated. As shown in Table 1, the best neural network for turbidity variations was obtained based on the lowest error and the highest correlation coefficient with a hidden layer in the Levenberg learning law and with the tangent transfer function in Neuron 8.

Also for color variations, the network with the number of neurons 9 under the Levenberg learning law and the tangent transfer function showed the highest correlation coefficient and the lowest error (Table 2).

According to Table 3, the best artificial neural network structure was developed for purity of refined syrup changes in the number of neurons 17 and the Levenberge learning law and the Tangent transfer function.

Table 4 compares the best structure of artificial neural network based on the highest correlation coefficient and the lowest error under the two laws of learning Levenberg and Momentom, as well as the tangent and sigmoid transfer functions for the changes in the turbidity, color and purity of raw syrup treated by electrocoagulation.

Hakimzadeh et al. (2017) obtained the best result to predict the properties of permeate flow as refined syrup at range of 2-20 neuron under levenberg and momentum learning law during modeling of microfiltration process of raw sugar beet juice by neural network. 
Table 1

Different architectures of ANN with different neurons number under the Levenberg learning law and two transfer functions to predict the turbidity of refined raw sugar beet juice by EC process

\begin{tabular}{|c|c|c|c|c|c|c|c|c|}
\hline Turbidity & \multicolumn{9}{|c|}{ Sigmoid } & \multicolumn{4}{c|}{ Tangent } \\
\hline $\begin{array}{c}\text { No of } \\
\text { neurons }\end{array}$ & \multicolumn{9}{|c|}{ MSE } & NMSE & MAE & R & MSE & NMSE & MAE & R \\
\cline { 2 - 9 } & MSenberg \\
\hline 2 & 3.386 & 0.634 & 1.578 & 0.628 & 1.267 & 0.237 & 0.951 & 0.948 \\
\hline 3 & 3.467 & 0.649 & 1.546 & 0.615 & 1.039 & 0.194 & 0.811 & 0.945 \\
\hline 4 & 0.310 & 0.058 & 0.462 & 0.947 & 0.965 & 0.181 & 0.829 & 0.965 \\
\hline 5 & 4.230 & 0.793 & 1.216 & 0.727 & 0.867 & 0.162 & 0.766 & 0.940 \\
\hline 6 & 1.733 & 0.324 & 0.894 & 0.830 & 1.727 & 0.323 & 1.080 & 0.854 \\
\hline 7 & 0.144 & 0.027 & 0.275 & 0.987 & 0.820 & 0.153 & 0.807 & 0.935 \\
\hline $\mathbf{8}$ & 3.596 & 0.674 & 1.709 & 0.924 & $\mathbf{0 . 1 7 7}$ & $\mathbf{0 . 0 3 3}$ & $\mathbf{0 . 3 2 7}$ & $\mathbf{0 . 9 8 9}$ \\
\hline 9 & 0.231 & 0.043 & 0.395 & 0.981 & 0.297 & 0.055 & 0.418 & 0.977 \\
\hline 10 & 1.485 & 0.278 & 0.847 & 0.858 & 1.362 & 0.255 & 0.964 & 0.929 \\
\hline 11 & 2.458 & 0.460 & 1.381 & 0.895 & 1.895 & 0.355 & 1.128 & 0.922 \\
\hline 12 & 1.135 & 0.212 & 0.825 & 0.947 & 0.649 & 0.121 & 0.639 & 0.946 \\
\hline 13 & 0.892 & 0.167 & 0.861 & 0.957 & 0.836 & 0.156 & 0.719 & 0.956 \\
\hline 14 & 4.828 & 0.905 & 1.736 & 0.917 & 1.065 & 0.199 & 0.771 & 0.959 \\
\hline 15 & 0.486 & 0.091 & 0.480 & 0.962 & 0.491 & 0.092 & 0.592 & 0.966 \\
\hline 16 & 3.598 & 0.647 & 1.606 & 0.784 & 0.188 & 0.035 & 0.326 & 0.982 \\
\hline 17 & 0.207 & 0.038 & 0.353 & 0.984 & 0.274 & 0.051 & 0.405 & 0.974 \\
\hline 18 & 0.945 & 0.177 & 0.779 & 0.949 & 0.261 & 0.049 & 0.434 & 0.986 \\
\hline 19 & 5.590 & 1.047 & 1.928 & 0.336 & 0.444 & 0.083 & 0.547 & 0.978 \\
\hline 20 & 5.545 & 1.039 & 2.054 & 0.787 & 4.760 & 0.892 & 1.543 & 0.654 \\
\hline
\end{tabular}

Table 2

Different architectures of ANN with different neurons number under the Levenberg learning law and two transfer functions to predict the color of raw sugar beet juice by EC process

\begin{tabular}{|c|c|c|c|c|c|c|c|c|}
\hline \multirow{3}{*}{$\begin{array}{c}\text { Color } \\
\text { No of } \\
\text { neurons }\end{array}$} & \multicolumn{8}{|c|}{ Levenberg } \\
\hline & \multicolumn{4}{|c|}{ Sigmoid } & \multicolumn{4}{|c|}{ Tanh } \\
\hline & MSE & NMSE & MAE & $\mathbf{R}$ & MSE & NMSE & MAE & $\mathbf{R}$ \\
\hline 2 & 386701.6 & 0.642 & 600.833 & 0.641 & 539031.71 & 0.896 & 671.55 & 0.414 \\
\hline 3 & 481401.7 & 0.800 & 677.616 & 0.518 & 837038.36 & 1.391 & 798.94 & 0.247 \\
\hline 4 & 1529648.7 & 2.543 & 1034.30 & 0.489 & 494674.09 & 0.822 & 646.51 & 0.588 \\
\hline 5 & 728191.02 & 1.210 & 640.182 & 0.568 & 439126.5 & 0.730 & 560.42 & 0.565 \\
\hline 6 & 293851.45 & 0.488 & 416.781 & 0.786 & 792885.19 & 1.318 & 754.42 & 0.723 \\
\hline 7 & 103790.12 & 0.172 & 184.883 & 0.935 & 941667.79 & 1.565 & 684.78 & 0.637 \\
\hline 8 & 1170664.6 & 1.946 & 901.680 & 0.636 & 159732.29 & 0.265 & 299.67 & 0.914 \\
\hline 9 & 68162.75 & 0.113 & 198.121 & 0.946 & 142774.3 & 0.237 & 288.32 & 0.888 \\
\hline 10 & 1051676.8 & 1.748 & 873.264 & 0.483 & 318157.8 & 0.529 & 492.41 & 0.716 \\
\hline 11 & 1476475.8 & 2.454 & 1028.44 & 0.503 & 525539.87 & 0.873 & 607.50 & 0.504 \\
\hline 12 & 772007.309 & 1.283 & 721.465 & 0.674 & 400089.82 & 0.665 & 444.60 & 0.817 \\
\hline 13 & 374009.843 & 0.621 & 526.942 & 0.898 & 675619.29 & 1.123 & 691.05 & 0.778 \\
\hline 14 & 711061.9 & 1.182 & 736.124 & 0.526 & 737711.02 & 1.226 & 800.39 & 0.411 \\
\hline 15 & 412772.328 & 0.686 & 499.186 & 0.762 & 468735.99 & 0.779 & 584.80 & 0.700 \\
\hline 16 & 1206713.9 & 2.006 & 861.404 & 0.458 & 116272.43 & 0.193 & 210.91 & 0.929 \\
\hline 17 & 111442.18 & 0.185 & 241.737 & 0.937 & 137922.04 & 0.229 & 275.75 & 0.911 \\
\hline 18 & 1018876.13 & 1.694 & 840.285 & 0.695 & 394542.395 & 0.656 & 509.35 & 0.800 \\
\hline 19 & 971547.29 & 1.615 & 882.676 & 0.831 & 197761.07 & 0.328 & 355.38 & 0.904 \\
\hline 20 & 1195237.1 & 1.987 & 925.999 & 0.593 & 1141003.26 & 1.897 & 882.00 & 0.521 \\
\hline
\end{tabular}


Table 3

Different architectures of ANN with different neurons number under the Levenberg learning law and two transfer functions to predict the purity of refined raw sugar beet juice by EC process

\begin{tabular}{|c|c|c|c|c|c|c|c|c|}
\hline Purity & \multicolumn{9}{|c|}{ Levenberg } \\
\hline \multirow{2}{*}{$\begin{array}{c}\text { No of } \\
\text { neurons }\end{array}$} & \multicolumn{3}{|c|}{ Sigmoid } & \multicolumn{4}{c|}{ Tanh } \\
\cline { 2 - 9 } & MSE & NMSE & MAE & r & MSE & NMSE & MAE & R \\
\hline 2 & 0.038 & 0.203 & 0.141 & 0.893 & 0.070 & 0.377 & 0.212 & 0.813 \\
\hline 3 & 0.069 & 0.370 & 0.224 & 0.802 & 0.083 & 0.448 & 0.235 & 0.791 \\
\hline 4 & 0.095 & 0.511 & 0.243 & 0.753 & 0.073 & 0.390 & 0.221 & 0.858 \\
\hline 5 & 0.227 & 1.216 & 0.312 & 0.540 & 0.076 & 0.408 & 0.233 & 0.777 \\
\hline 6 & 0.131 & 0.701 & 0.313 & 0.765 & 0.144 & 0.772 & 0.328 & 0.690 \\
\hline 7 & 0.049 & 0.263 & 0.163 & 0.879 & 0.330 & 1.764 & 0.454 & 0.427 \\
\hline 8 & 0.216 & 1.157 & 0.382 & 0.364 & 0.090 & 0.484 & 0.231 & 0.796 \\
\hline $\mathbf{9}$ & $\mathbf{0 . 0 4 4}$ & $\mathbf{0 . 2 3 6}$ & $\mathbf{0 . 1 4 8}$ & $\mathbf{0 . 9 0 0}$ & 0.038 & 0.207 & 0.145 & 0.902 \\
\hline 10 & 0.145 & 0.774 & 0.276 & 0.658 & 0.136 & 0.726 & 0.297 & 0.670 \\
\hline 11 & 0.162 & 0.868 & 0.302 & 0.616 & 0.039 & 0.208 & 0.151 & 0.895 \\
\hline 12 & 0.090 & 0.485 & 0.214 & 0.832 & 0.111 & 0.594 & 0.248 & 0.780 \\
\hline 13 & 0.056 & 0.300 & 0.168 & 0.856 & 0.049 & 0.263 & 0.164 & 0.923 \\
\hline 14 & 0.120 & 0.640 & 0.288 & 0.643 & 0.136 & 0.727 & 0.298 & 0.827 \\
\hline 15 & 0.096 & 0.515 & 0.263 & 0.724 & 0.073 & 0.389 & 0.240 & 0.855 \\
\hline 16 & 0.411 & 2.193 & 0.526 & 0.633 & 0.068 & 0.366 & 0.168 & 0.845 \\
\hline $\mathbf{1 7}$ & 0.069 & 0.370 & 0.224 & 0.861 & $\mathbf{0 . 0 3 0}$ & $\mathbf{0 . 1 6 4}$ & $\mathbf{0 . 1 3 0}$ & $\mathbf{0 . 9 3 0}$ \\
\hline 18 & 0.068 & 0.367 & 0.217 & 0.841 & 0.126 & 0.673 & 0.256 & 0.737 \\
\hline 19 & 0.159 & 0.853 & 0.342 & 0.843 & 0.063 & 0.338 & 0.173 & 0.877 \\
\hline 20 & 0.147 & 0.787 & 0.309 & 0.525 & 0.350 & 1.867 & 0.491 & 0.586 \\
\hline
\end{tabular}

Table 4

Comparison of two learning rules used for selection of the best ANN architectures to predict the Turbidity, Color and Purity in refined raw sugar beet juice by EC process

\begin{tabular}{|c|c|c|c|c|c|c|}
\hline \multirow{2}{*}{ Parameter } & \multicolumn{7}{|c|}{ Levenberg } & Transfer \\
\cline { 2 - 7 } & $\begin{array}{c}\text { Number of } \\
\text { neuron }\end{array}$ & $\begin{array}{c}\text { Munction } \\
\text { funE }\end{array}$ & NMSE & MAE & r \\
\hline Turbidity & 8 & Tangent & 0.177 & 0.033 & 0.327 & 0.986 \\
\hline Color & 9 & sigmoid & 68162.750 & 0.113 & 198.121 & 0.946 \\
\hline Purity & 17 & Tangent & 0.030 & 0.164 & 0.130 & 0.930 \\
\hline & 18 & Tangent & 0.701 & 0.131 & 0.682 & 0.983 \\
\hline Turbidity & 7 & sigmoid & 693058.41 & 1.152 & 635.673 & 0.668 \\
\hline Color & 5 & Tangent & 0.068 & 0.367 & 0.219 & 0.830 \\
\hline Purity & 5
\end{tabular}




\section{Determination of training, validation and testing percentage}

Also, in ANN modeling of the turbidity, color and purity of refined syrup by electrocoagulation process different percentages of data for training, evaluation and testing was investigated. To this end, firstly, the most suitable data for training was selected according to the best correlation coefficient. Then, based on the best training percentage, the best percentages of data for validation and testing were also determinate (Tables 5 to 7).

Table5

Best percentages of data used for training, validation and testing of selected ANN architectures to model the turbidity of refined raw sugar beet juice by EC process

\begin{tabular}{|c|c|c|c|c|c|c|}
\hline $\begin{array}{c}\text { Training } \\
\text { Data (\%) }\end{array}$ & $\begin{array}{c}\text { Validation } \\
\text { Data (\%) }\end{array}$ & $\begin{array}{c}\text { Testing } \\
\text { Data (\%) }\end{array}$ & MSE & NMSE & MAE & R \\
\hline 55 & 5 & 40 & 0.362 & 0.063 & 0.507 & 0.978 \\
\hline 55 & 10 & 35 & 0.548 & 0.104 & 0.514 & 0.949 \\
\hline 55 & 15 & 30 & 0.276 & 0.048 & 0.460 & 0.981 \\
\hline 55 & 20 & 25 & 0.320 & 0.062 & 0.458 & 0.974 \\
\hline 55 & 25 & 20 & 1.450 & 0.252 & 0.835 & 0.890 \\
\hline 55 & 30 & 15 & 0.092 & 0.017 & 0.236 & 0.997 \\
\hline 55 & 35 & 10 & 0.023 & 0.006 & 0.137 & 0.998 \\
\hline 55 & $\mathbf{4 0}$ & $\mathbf{5}$ & $\mathbf{0 . 0 1 7}$ & $\mathbf{0 . 0 0 4}$ & $\mathbf{0 . 1 0 9}$ & $\mathbf{0 . 9 9 9}$ \\
\hline
\end{tabular}

Table6

Best percentages of data used for training, validation and testing of selected ANN architectures to model the color of refined raw sugar beet juice by EC process

\begin{tabular}{|c|c|c|c|c|c|c|}
\hline $\begin{array}{c}\text { Training } \\
\text { Data (\%) }\end{array}$ & $\begin{array}{c}\text { Validation } \\
\text { Data (\%) }\end{array}$ & $\begin{array}{c}\text { Testing } \\
\text { Data (\%) }\end{array}$ & MSE & NMSE & MAE & R \\
\hline 60 & 5 & 35 & 501238.39 & 0.556 & 502.473 & 0.775 \\
\hline 60 & 10 & 30 & 38912.695 & 0.047 & 149.673 & 0.982 \\
\hline 60 & 15 & 25 & 20725.932 & 0.027 & 120.483 & 0.988 \\
\hline 60 & 20 & 20 & 32706.608 & 0.065 & 139.694 & 0.975 \\
\hline 60 & 25 & 15 & 60699.965 & 0.124 & 210.322 & 0.962 \\
\hline $\mathbf{6 0}$ & $\mathbf{3 0}$ & $\mathbf{1 0}$ & $\mathbf{8 4 4 6 2 . 2 8 0}$ & $\mathbf{0 . 1 5 4}$ & $\mathbf{2 1 6 . 5 6 0}$ & $\mathbf{0 . 9 9 8}$ \\
\hline 60 & 35 & 5 & 56360.277 & 0.105 & 170.445 & 0.993 \\
\hline
\end{tabular}

Table7

Best percentages of data used for training, validation and testing of selected ANN architectures to model the purity of refined raw sugar beet juice by $\mathrm{EC}$ process

\begin{tabular}{|c|c|c|c|c|c|c|}
\hline $\begin{array}{c}\text { Training } \\
\text { Data (\%) }\end{array}$ & $\begin{array}{c}\text { Validation } \\
\text { Data (\%) }\end{array}$ & $\begin{array}{c}\text { Testing } \\
\text { Data (\%) }\end{array}$ & MSE & NMSE & MAE & R \\
\hline 55 & 5 & 45 & 0.062 & 0.309 & 0.198 & 0.873 \\
\hline 55 & 10 & 35 & 0.008 & 0.036 & 0.075 & 0.983 \\
\hline 55 & 15 & 30 & 0.015 & 0.068 & 0.095 & 0.974 \\
\hline 55 & 20 & 25 & 0.044 & 0.197 & 0.155 & 0.907 \\
\hline 55 & 25 & 20 & 0.036 & 0.182 & 0.168 & 0.924 \\
\hline 55 & 30 & 15 & 0.021 & 0.121 & 0.131 & 0.942 \\
\hline 55 & 35 & 10 & 0.014 & 0.053 & 0.116 & 0.992 \\
\hline 55 & $\mathbf{4 0}$ & $\mathbf{5}$ & $\mathbf{0 . 0 2 4}$ & $\mathbf{0 . 2 0 9}$ & $\mathbf{0 . 1 4 1}$ & $\mathbf{0 . 9 9 4}$ \\
\hline
\end{tabular}


Usually an effectiveness model to predict the reliable data need sufficient data for good learning that has to be over 50 percent of whole data. In other world when learning a model to get done right, the predicted values will be valuable (Jaganathan, 2017)

\section{Investigating of neural network potential to predict data}

Figure 1 shows the correlation graph of laboratory values with predicted values by the model. Accordingly, models obtained from artificial neural network to predict turbidity, color and purity were able to correlate with appropriate coefficients of 0.998, 0.996 and 0.990 , respectively.

\section{Turbidity (NTU)}

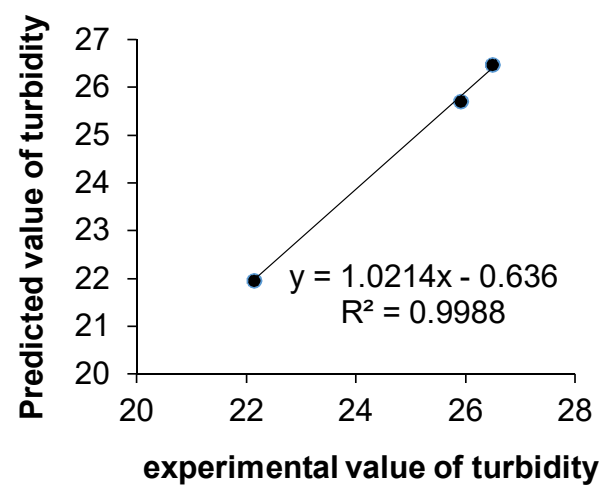

\section{Color (ICUMSA)}

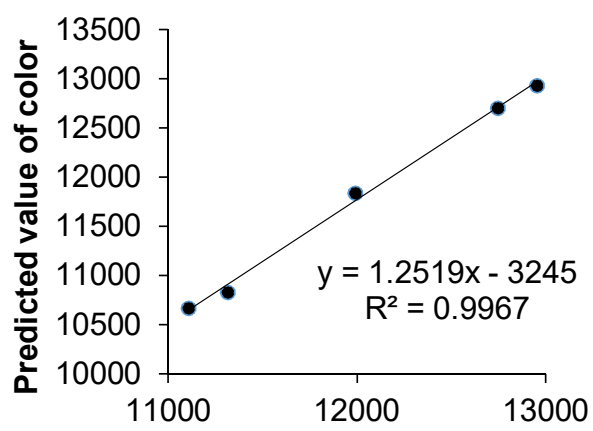

Experimental value of color

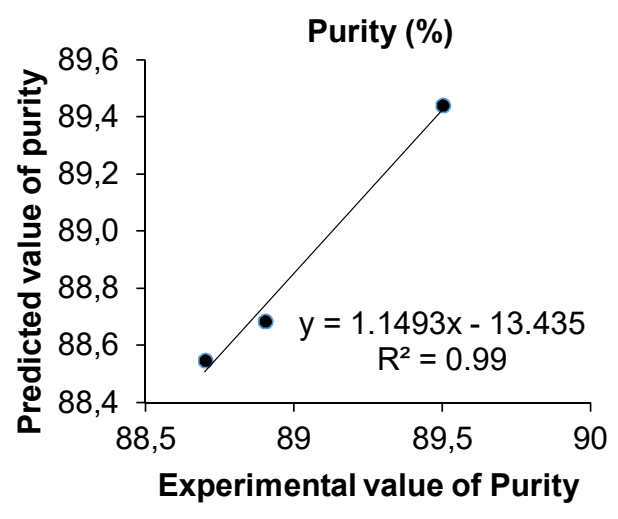

Figure 1. Correlation between experimental data and predicted values

\section{Determine the sensitivity of the model to the input data}

In this study, the susceptibility of the models to the operational variables, i.e., input data, was evaluated. According to Figure 2, the most sensitivity of model was to predict the turbidity, color and purity of the refined syrup with voltage electrocoagulation. 


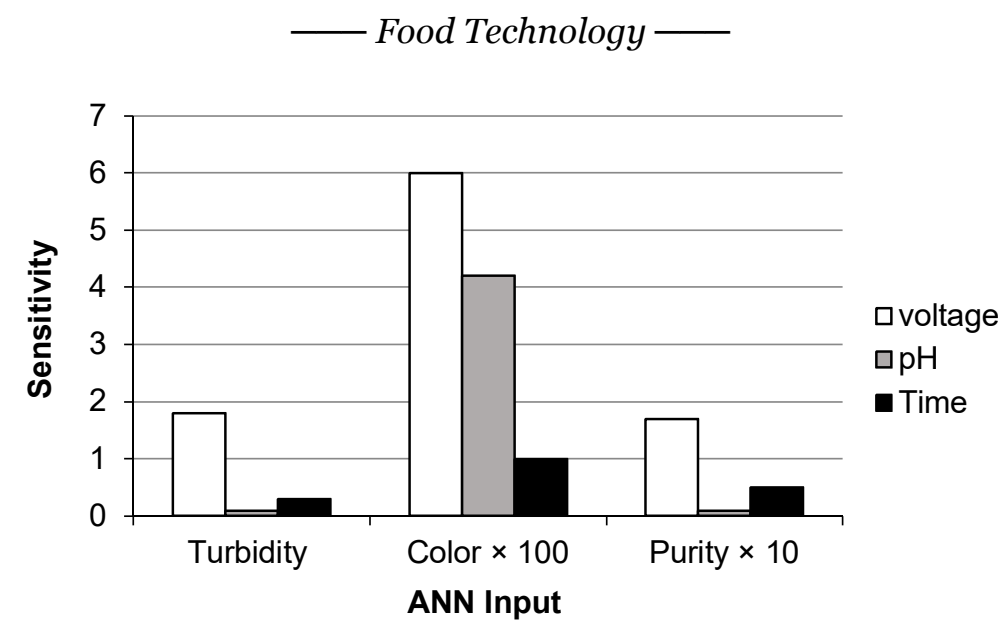

Figure 2. Models' sensitivity to prediction of turbidity, color and purity

Model's sensitivity to prediction of turbidity, color and purity due to voltage is so obvious. Because increasing of the voltage led to accelerate of anode and cathode reaction and consequently formation of flock (Ghanbari, 2013; Chaturvedi, 2013). So, with more flock forming, more impurities are absorbed on flocks and the turbidity, color and purity are improved. Shahidi et al (2011) reported the temperature as the best sensitive parameter to flux prediction during modeling of nanofiltration of sugar beet press water by artificial neural network. In membrane process increasing of temperature expand the pores diameter of membrane and the permeate flux is increased.

\section{Conclusion}

The results of electrocoagulation process modeling in purification of raw sugar beet syrup showed that the best learning law for network training to predict the Turbidity, color and purity was Levenberg law. So that the best transfer function for network design with the best prediction of the turbidity and purity value was the tangent and for prediction of color was sigmoid. The best percentage of data for learning, validation and testing of the model was obtained by predicting the turbidity and purity of the refined syrup by electrocoagulation, respectively, 55, 40 and 5, while for color 60,30 and $10 \%$ were determined. In general, the model was able to predict the turbidity, color and purity of the syrup under various operating conditions, as the modeling data showed a high correlation with the experimental data (Table 8)

Table 8

Summarized result of modeling of turbidity, color and purity changes in purification of raw beet juice by EC process

\begin{tabular}{|c|c|c|c|c|c|c|}
\hline $\begin{array}{c}\text { Dependent } \\
\text { variable }\end{array}$ & $\begin{array}{c}\text { Hidden } \\
\text { layer }\end{array}$ & $\begin{array}{c}\text { Number } \\
\text { of } \\
\text { neuron }\end{array}$ & $\begin{array}{c}\text { Transfer } \\
\text { function }\end{array}$ & $\begin{array}{c}\text { Learning } \\
\text { rule }\end{array}$ & $\begin{array}{c}\text { Percentage of } \\
\text { learning/ } \\
\text { validation/test }\end{array}$ & $\begin{array}{c}\text { Correlation } \\
\text { coefficient }\end{array}$ \\
\hline Turbidity & 1 & 8 & Tangent & Levenberge & $55 / 40 / 5$ & $\mathbf{1}$ \\
\hline Color & 1 & 9 & Sigmoid & Levenberge & $60 / 30 / 10$ & $\mathbf{1}$ \\
\hline Purity & 1 & 17 & Tangent & Levenberge & $55 / 40 / 5$ & $\mathbf{1}$ \\
\hline
\end{tabular}




\section{References}

1. Azizi H., Hakimzadeh V., Golestani H. (2016), Purification of Raw Sugar Beet Juice by Electrocoagulation, Ukrainian Food Journal, 5(4), pp. 667-677.

2. Bazrafshan E., Moein H., Kordmostafapour F., Nakhaie S. (2013), Application of Electrocoagulation Process for Dairy Wastewater Treatment, Journal of Chmistry, 64013, pp. 18

3. Chaturvedi S.I. (2013), Electrocoagulation: A Novel Wastewater Treatment Method, I. J. Modern Engineering Research, 3, 93-100.

4. Chen G. 2004), Electrochemical technologies in wastewater treatment, Separation Purification Technology, 38, pp. 11-41.

5. Delgrange N., Cabassud C., Cabassud M., Durand-Bourlier L., Lain J.M. (1998), Neural network for prediction of ultrafiltration transmembrane pressure application to drink water, Journal of Membrane Science, 150, pp. 111-123.

6. Emamjomeh M., Sivakumar M. (2009), Review of pollutants removed by electrocoagulation and electrocoagulation/flotation processes, Journal of Environmental Management, 90, 1663-1679.

7. Ghanbari F., Mazaheri A., Mehdipoor F., Mir Shafian S., Moradi M., Sharifi Maleksari H. (2013), Investigation of the effect of the electrocoagulation on the removal of colour from coloured sewage by using aluminium/iron and aluminium/copper electrodes, Journal of Sabzevar University of Medical Sciences, 20(5), pp. 716-725.

8. Jaganathan A., Kumar S.M. (2017), Artificial Neural Network Analysis in Food Science, International Research Journal of Engineering and Technology, 4(1), pp. 746-751.

9. Kobya M., Can O.T., Bayramoglu M. (2003), Treatment of textile wastewaters by electrocoagulation using iron and aluminum electrodes, J. Hazardous Material, 100, pp. 163178.

10. Malakootian M., Yousefi N. (2009), The Efficiency of EC Process Using Aluminum Electrodes in Removal of Hardness from water, Iran. J. Environ. Health. Sci. Eng., 6(2), pp. 131-136.

11. Menhaj M.B. (2000), Fundamental of neural networks, Computational illteligence, 1.

12. Myousuf A.M., Schennach R., Parga J.R., Cocke, D.L. (2001), Electrocoagulation (EC) Science and applications, Hazardous Materials, 84, pp. 29-41.

13. Parga J.R., Cocke D.L., Valenzuela J.L., Gomes J.A., Kesmez M., Irwin G., Moreno H., Weir M. (2005), Arsenic removal via Electrocoagulation from heavy metal contaminated groundwater in La Comarca Lagunera Mexico, Journal of Hazardous Material, 124(1-3), pp. 247-5.

14. Razavi S.M.A., Mousavi S.M., Mortazavi S.A. (2003), Dynamic prediction of milk ultrafiltration performance: a neural network approach, Chem. Eng. Sci., 58, pp. 4185-4195.

15. Shahidi Noghabi M., Razavi S.M.A, Mousavi S.M. (2012), Prediction of permeate flux and ionic compounds rejection of sugar beet press water nanofiltration using artificial neural networks, Desalination and Water Treatment, 44, 1-3, pp. 83-91.

16. Shivayogimath C.B., Jahagirdar R. (2013), Treatment of Sugar Industry Wastewater Using Electrocoagulation Technique, International Journal of Research in Engineering and Technology, pp. 262-265.

17. Xu L.J., Sheldon B.W., Larick D.K., Carawan R.E. (2002), Recovery and Utilization of Useful By-products from Egg Processing Wastewater by Electrocoagulation, Poultry science, 81(6), pp. 785-792. 